\title{
Obesity and COVID-19
}

\author{
Domenico Azzolino * and Matteo Cesari \\ Department of Clinical Sciences and Community Health, University of Milan, Milan, Italy
}

Keywords: aging, inflammation, nutrition, SARS - CoV-2, body mass Index, sarcopenic obesity, ACE2 (Angiotensin Converting Enzyme-2)

The global pandemic of COVID-19 is putting a strain on the weakness of health care systems. The lack of an established treatment against COVID-19 infection and the rationing of care resulted in a dramatic scenario. Patients with COVID-19 present with very heterogeneous symptoms from asymptomatic forms to severe acute respiratory distress. Infected patients are more likely to have elevated levels of inflammatory markers, and most of those developing severe forms of the disease require mechanical ventilation. The worst-hit population comprises older people and those with multimorbidity. In particular, obesity (usually measured with body mass index, BMI) is repeatedly reported as a major risk factor for severe complications of COVID-19 $(1,2)$, including respiratory failure, the need for invasive mechanical ventilation, and death (3).

The role of obesity is of great relevance, especially given its high prevalence worldwide. However,

OPEN ACCESS

Edited by:

Massimiliano Caprio,

Università telematica San Raffaele, Italy

Reviewed by:

Caterina Conte,

Università telematica San Raffaele, Italy

${ }^{*}$ Correspondence:

Domenico Azzolino

domenico.azzolino@unimi.it

Specialty section: This article was submitted to

Obesity,

a section of the journal

Frontiers in Endocrinology

Received: 08 July 2020 Accepted: 08 September 2020 Published: 30 September 2020

Citation:

Azzolino D and Cesari M (2020)

Obesity and COVID-19.

Front. Endocrinol. 11:581356. doi: 10.3389/fendo.2020.581356 it is important to bear in mind that the assessment of obesity via BMI is extremely arguable, especially in older people. First, it should be noted that BMI does not purely reflect adiposity because its numerator (i.e., body weight) results from the sum of both fat and fat-free mass. Second, the cut points used to categorize overweight and obesity are arbitrary and based on young and middle-aged cohorts and are, thus, inadequate for older persons (4). Third, with aging, body fat tends to accumulate in parallel with the muscle mass decline. Consequently, obesity is often underestimated in older persons, who may present an excess of adiposity within a normal/overweight body size (the so-called sarcopenic obesity) (5). Finally, ethnic difference may determine major variability in body fat distribution, in particular for what concerns ectopic and visceral fat (4). Body composition is an important aspect to consider in older persons, but it is something not easy to routinely assess even in normal times. Preventive strategies for limiting the spread of the coronavirus as well as the scarce attention frequently given to this evaluation may further accentuate this issue in the period of COVID-19. For this reason, whereas the most accurate techniques (e.g., magnetic resonance imaging, computed tomography, dual energy X-ray absorptiometry) may be difficult to implement or unfeasible during a pandemic, alternatives coming from less accurate methodologies (e.g., bioelectrical impedance analysis) and/or surrogate parameters (e.g., estimates coming from prediction equations) should be considered $(6,7)$.

Although evidence is still very limited, several reports are starting to indicate a role for adiposity in the COVID-19 susceptibility and severity. Just recently, Watanabe et al. (8) find that visceral fat was significantly higher in COVID-19 patients requiring ICU support-together with age, inflammation markers, and interstitial pneumonia severity. Similarly, Battisti et al. (9) report that COVID-19 severity is associated with abdominal adipose tissue distribution. In another recent study (10), the authors find a positive association between visceral adipose tissue and upper abdominal circumference with COVID-19 severity. What is more, Yang et al. (11) document that, in COVID- 
19 patients, visceral adiposity or high intramuscular fat deposition increases the risk for critical illness.

The contribution of obesity to the severity of COVID-19 may be explained in multiple ways. Obesity is a well-recognized risk factor for diabetes, hypertension, and cardiovascular disease, all of which are predictors of poor outcomes in COVID-19 (12). Obesity may also impair immune response to viral infections and affect diaphragm excursion (thus causing dysventilation) $(3,13)$. Additionally, the management of obese patients with COVID-19 might be more challenging than routine because the patient's size may limit medical and assistive procedures.

Furthermore, obesity is characterized by abnormal secretion of adipokines and cytokines determining a low-grade systemic inflammation, which may represent the background predisposition to the most severe consequences of COVID-19 (3). At the same time, chronic low-grade inflammation represents a hallmark of aging, responsible for altered metabolism (i.e., elevation of resting energy expenditure) and increased muscle catabolism $(14,15)$. Inflammation could be the key factor of the muscle decline observed in older individuals, which can be further exacerbated in those with obesity (16). Obesity may also lead to increased fat infiltration of the muscle associated with a decrease in muscle strength and function, mainly due to physical inactivity of obese individuals. As a consequence, muscle decline may lead to a decrease in physical activity, which, in turn, promotes obesity with consequent increased catabolism and anabolic resistance, thus creating a vicious circle of muscle decline (17). In fact, fat mass increase usually precedes a loss of muscle mass. In other words, the increase of adiposity (especially in visceral fat) along with the low-grade chronic inflammation seen with aging could have even more detrimental effects and determine an accelerated muscle decline. Interestingly, intermuscular adipose tissue is shown to contribute to physical impairment, enhancement of insulin resistance, and increased the risk of negative health-related events (18).

Additionally, an association between the SARS-CoV-2 infection and the angiotensin-converting enzyme 2 (ACE2) receptor is widely reported, potentially playing a critical role in the pathological pathway (19-21). Interestingly, the expression of the ACE2 receptor is particularly present in adipose tissue (22, 23), possibly explaining the higher susceptibility, greater severity, and worse prognosis for COVID-19 infection in obese patients $(23,24)$. A controversy, however, exists about the protective or deleterious role of angiotensin-converting enzyme inhibitors (ACEIs) and angiotensin receptor blockers (ARBs) in COVID19 (21).

In this global pandemic, the negative effects of obesity are not confined solely to the acute care setting. In fact, the need for

\section{REFERENCES}

1. Gandhi RT, Lynch JB, Del Rio C. Mild or Moderate Covid-19. N Engl J Med (2020). doi: 10.1056/NEJMcp2009249

2. Stefan N, Birkenfeld AL, Schulze MB, Ludwig DS. Obesity and impaired metabolic health in patients with COVID-19. Nat Rev Endocrinol (2020) 16 (7):341-2. doi: 10.1038/s41574-020-0364-6 social distancing and isolation during the lockdown may exacerbate depressive symptoms. Furthermore, self-isolation may increase the barriers to accessing healthy and fresh foods with a net shift toward convenience foods, especially in people with a poor socioeconomic status. The self-isolation period due to the lockdown may also lead to the deterioration of the circadian rhythm, resulting in a change of eating habits. Obesity has been widely related to sleep alteration and vice versa (25). In fact, sleep disorders can result in metabolic (i.e., decreased glucose tolerance and insulin sensitivity) and endocrine alterations (i.e., reduced leptin levels, high evening concentrations of cortisol, ghrelin, and increased hunger and appetite), all of which promote obesity (26). Sleep disturbances may also result from high circulating levels of pro-inflammatory cytokines, which are a hallmark of obesity (27). Additionally, high-fat and high-carbohydrate meals may alter sleep indexes (26-29) via the elevation of the circulating levels of glucose, insulin, leptin, cholecystokinin (CCK), peptide YY, and enterostatin (28-30).

On the other hand, it should not be neglected that obese individuals may suffer from stigma and depressive symptoms already in normal times. This may render them more likely to restrict their social contacts with detrimental consequences to their physical and psychological domains in the period of COVID-19 (31).

In conclusion, it is necessary that special attention is paid to prevent and control the COVID-19 infection in specific populations, such as obese and older persons, who are already exposed to basal inflammatory status. Inflammation, which is a hallmark of both obesity and the aging process, might have a synergistic role in promoting greater severity of COVID-19. However, as discussed, obesity measured with BMI does not necessarily reflect adiposity. Indeed, it is important to bear in mind that even though the box may look the same, the contents may be different. In this case, it would be better to think inside the box. The role of obesity in COVID-19, given the burden it poses, must no longer be ignored and may have major implications in the public health strategy.

\section{AUTHOR CONTRIBUTIONS}

DA contributed to conceptualizing and writing the manuscript. MC edited and revised manuscript. DA and MC approved the final version of manuscript. All authors contributed to the article and approved the submitted version.
3. Sattar N, McInnes IB, McMurray JJV. Obesity a Risk Factor for Severe COVID-19 Infection: Multiple Potential Mechanisms. Circulation (2020) 142 (1):4-6. doi: 10.1161/CIRCULATIONAHA.120.047659

4. Ng TP, Jin A, Chow KY, Feng L, Nyunt MSZ, Yap KB. Age-dependent relationships between body mass index and mortality: Singapore longitudinal ageing study. PloS One (2017) 12(7):e0180818. doi: 10.1371/ journal.pone.0180818 
5. Cruz-Jentoft AJ, Sayer AA. Sarcopenia. Lancet (2019) 393(10191):2636-46. doi: 10.1016/S0140-6736(19)31138-9

6. Barazzoni R, Bischoff SC, Breda J, Wickramasinghe K, Krznaric Z, Nitzan D, et al. ESPEN expert statements and practical guidance for nutritional management of individuals with SARS-CoV-2 infection. Clin Nutr (2020), 39(6):1631-8. doi: 10.1016/j.clnu.2020.03.022

7. Singer P. Protein metabolism and requirements in the ICU. Clin Nutr ESPEN (2020) 38:3-8. doi: 10.1016/j.clnesp.2020.03.026

8. Watanabe M, Caruso D, Tuccinardi D, Risi R, Zerunian M, Polici M, et al. Visceral fat shows the strongest association with the need of intensive Care in Patients with COVID-19. Metabolism (2020) 111:154319. doi: 10.1016/ j.metabol.2020.154319

9. Battisti S, Pedone C, Napoli N, Russo E, Agnoletti V, Nigra SG, et al. Computed Tomography Highlights Increased Visceral Adiposity Associated With Critical Illness in COVID-19. Diabetes Care (2020) 43(10):e129-30. doi: 10.2337/dc201333

10. Petersen A, Bressem K, Albrecht J, Thieß H-M, Vahldiek J, Hamm B, et al. The role of visceral adiposity in the severity of COVID-19: Highlights from a unicenter cross-sectional pilot study in Germany. Metabolism (2020) 110:154317. doi: 10.1016/j.metabol.2020.154317

11. Yang Y, Ding L, Zou X, Shen Y, Hu D, Hu X, et al. Visceral Adiposity and High Intramuscular Fat Deposition Independently Predict Critical Illness in Patients with Sars-COV-2. Obesity. cited 2020 Aug 20];n/a(n/a). doi: 10.1002/ oby.22971

12. Bornstein SR, Dalan R, Hopkins D, Mingrone G, Boehm BO. Endocrine and metabolic link to coronavirus infection. Nat Rev Endocrinol (2020) 16(6):2978. doi: 10.1038/s41574-020-0353-9

13. Kass DA, Duggal P, Cingolani O. Obesity could shift severe COVID-19 disease to younger ages. Lancet (2020) 395(10236):1544-5. doi: 10.1016/S0140-6736(20) 31024-2

14. Dalle S, Rossmeislova L, Koppo K. The Role of Inflammation in Age-Related Sarcopenia. Front Physiol (2017) 12(8):1045. doi: 10.3389/fphys.2017.01045

15. Lacourt TE, Vichaya EG, Chiu GS, Dantzer R, Heijnen CJ. The High Costs of Low-Grade Inflammation: Persistent Fatigue as a Consequence of Reduced Cellular-Energy Availability and Non-adaptive Energy Expenditure. Front Behav Neurosci (2018) 12:78. doi: 10.3389/fnbeh.2018.00078

16. Roh E, Choi KM. Health Consequences of Sarcopenic Obesity: A Narrative Review. Front Endocrinol (Lausanne) (2020) 11:332. doi: 10.3389/fendo.2020.00332

17. Stenholm S, Harris TB, Rantanen T, Visser M, Kritchevsky SB, Ferrucci L. Sarcopenic obesity: definition, cause and consequences. Curr Opin Clin Nutr Metab Care (2008) 11(6):693-700. doi: 10.1097/MCO.0b013e328312c37d

18. Addison O, Marcus RL, Lastayo PC, Ryan AS. Intermuscular fat: a review of the consequences and causes. Int J Endocrinol (2014) 2014:309570. doi: $10.1155 / 2014 / 309570$

19. Li W, Moore MJ, Vasilieva N, Sui J, Wong SK, Berne MA, et al. Angiotensinconverting enzyme 2 is a functional receptor for the SARS coronavirus. Nature (2003) 426(6965):450-4. doi: 10.1038/nature02145
20. Mehta N, Kalra A, Nowacki AS, Anjewierden S, Han Z, Bhat P, et al. Association of Use of Angiotensin-Converting Enzyme Inhibitors and Angiotensin II Receptor Blockers With Testing Positive for Coronavirus Disease 2019 (COVID-19). JAMA Cardiol (2020) 5(9):1020-6. doi: 10.1001/ jamacardio.2020.1855

21. Bavishi C, Maddox TM, Messerli FH. Coronavirus Disease 2019 (COVID-19) Infection and Renin Angiotensin System Blockers. JAMA Cardiol (2020) 5 (7):745-7. doi: 10.1001/jamacardio.2020.1282

22. Li M-Y, Li L, Zhang Y, Wang X-S. Expression of the SARS-CoV-2 cell receptor gene ACE2 in a wide variety of human tissues. Infect Dis Poverty (2020) 9(1):45. doi: 10.1186/s40249-020-00662-x

23. Al-Benna S. Association of high level gene expression of ACE2 in adipose tissue with mortality of COVID-19 infection in obese patients. Obes Med (2020) 19:100283. doi: 10.1016/j.obmed.2020.100283

24. Jia X, Yin C, Lu S, Chen Y, Liu Q, Bai J, et al. Two Things about COVID-19 Might Need Attention. (2020). doi: 10.20944/preprints202002.0315.v1

25. Vgontzas AN, Bixler EO, Chrousos GP, Pejovic S. Obesity and sleep disturbances: Meaningful sub-typing of obesity. Arch Physiol Biochem (2008) 114(4):224-36. doi: 10.1080/13813450802521507

26. Beccuti G, Pannain S. Sleep and obesity. Curr Opin Clin Nutr Metab Care (2011) 14(4):402-12. doi: 10.1097/MCO.0b013e3283479109

27. Vgontzas AN, Papanicolaou DA, Bixler EO, Kales A, Tyson K, Chrousos GP. Elevation of Plasma Cytokines in Disorders of Excessive Daytime Sleepiness: Role of Sleep Disturbance and Obesity. J Clin Endocrinol Metab (1997) 82(5):4. doi: 10.1210/jcem.82.5.3950

28. Panossian LA, Veasey SC. Daytime Sleepiness in Obesity: Mechanisms Beyond Obstructive Sleep Apnea-A Review. Sleep (2012) 35(5):605-15. doi: 10.5665/sleep. 1812

29. O’Reilly GA, Belcher BR, Davis JN, Martinez LT, Huh J, Antunez-Castillo L, et al. Effects of high-sugar and high-fiber meals on physical activity behaviors in Latino and African American adolescents: Dietary Sugar and Activity in Minority Adolescents. Obesity (2015) 23(9):1886-94. doi: 10.1002/oby.21169

30. St-Onge M-P, Mikic A, Pietrolungo CE. Effects of Diet on Sleep Quality. Adv Nutrit (2016) 7(5):938-49. doi: 10.3945/an.116.012336

31. Ryan DH, Ravussin E, Heymsfield S. COVID 19 and the Patient with Obesity The Editors Speak Out. Obesity (2020) 28(5):847-7. doi: 10.1002/oby.22808

Conflict of Interest: The authors declare that the research was conducted in the absence of any commercial or financial relationships that could be construed as a potential conflict of interest.

Copyright (๑) 2020 Azzolino and Cesari. This is an open-access article distributed under the terms of the Creative Commons Attribution License (CC BY). The use, distribution or reproduction in other forums is permitted, provided the original author $(s)$ and the copyright owner(s) are credited and that the original publication in this journal is cited, in accordance with accepted academic practice. No use, distribution or reproduction is permitted which does not comply with these terms. 